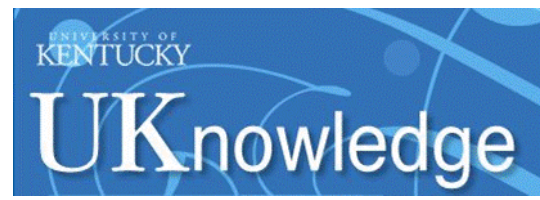

University of Kentucky

UKnowledge

$1-20-2018$

\title{
Accurate Location of Evolving Faults on Transmission Lines Using Sparse Wide Area Measurements
}

Xiangqing Jiao

University of Kentucky, xiangqing.jiao@gmail.com

Yuan Liao

University of Kentucky, yuan.liao@uky.edu

Follow this and additional works at: https://uknowledge.uky.edu/ece_facpub

Part of the Electrical and Electronics Commons, and the Power and Energy Commons

Right click to open a feedback form in a new tab to let us know how this document benefits you.

\section{Repository Citation}

Jiao, Xiangqing and Liao, Yuan, "Accurate Location of Evolving Faults on Transmission Lines Using Sparse Wide Area Measurements" (2018). Electrical and Computer Engineering Faculty Publications. 21.

https://uknowledge.uky.edu/ece_facpub/21

This Article is brought to you for free and open access by the Electrical and Computer Engineering at UKnowledge. It has been accepted for inclusion in Electrical and Computer Engineering Faculty Publications by an authorized administrator of UKnowledge. For more information, please contact UKnowledge@lsv.uky.edu. 


\section{Accurate Location of Evolving Faults on Transmission Lines Using Sparse Wide Area Measurements}

Digital Object Identifier (DOI)

https://doi.org/10.1515/ijeeps-2017-0244

\section{Notes/Citation Information}

Published in International Journal of Emerging Electric Power Systems, v. 19, issue 1, 20170244, p. 1-11.

(C) 2018 Walter de Gruyter GmbH, Berlin/Boston.

The copyright holder has granted the permission for posting the article here. 


\title{
Accurate Location of Evolving Faults on Transmission Lines Using Sparse Wide Area Measurements
}

\author{
${ }^{1}$ Department of ECE,University of Kentucky, Lexington, KY 40506, USA, E-mail: xiangqing.jiao@gmail.com, \\ yliao@engr.uky.edu
}

\begin{abstract}
:
In electric power systems, not all fault conditions remain unchanged during faults. An evolving fault has one characteristic initially and changes to a different condition subsequently. Locating evolving faults is challenging due to the change in fault type shortly after the fault initiation. This paper presents a new approach for estimating the locations of evolving faults on transmission lines. By using sparse wide area voltage measurements, this method is able to accurately locate evolving faults without requiring measurements from either end of the faulted line. There is no need to detect whether a fault is an evolving fault or not. Fault type information is not a necessity either, and the change of fault phases does not affect the estimation accuracy. In addition, the algorithm is applicable to both single-circuit and double-circuit lines, and the transmission lines can be either transposed or untransposed. Distributed parameter line model is adopted to fully consider the shunt capacitances of the transmission lines. Electromagnetic Transient Program (EMTP) is employed to simulate transmission system, and quite accurate results have been achieved.
\end{abstract}

Keywords: fault location, evolving fault, wide-area measurement

DOI: 10.1515/ijeeps-2017-0244

Received: November 17, 2017; Accepted: January 9, 2018

\section{Introduction}

Electric power transmission systems occasionally suffer from various short-circuit faults along transmission lines. Precise and fast fault location can facilitate maintenance, and reduce the outage time and accelerate power system restoration [1, 2]. Numerous algorithms have been developed in the past to estimate fault location in the transmission system [1-12, 14-16]. Most of the existing fault location algorithms assume the fault types are stationary over fault periods.

An evolving fault is defined as a fault where the phases involved change over time [17]. For example, an evolving fault begins as a single line-to-ground fault, and could become a line-to-line-to-ground fault after a few power frequency cycles [18, 19]. Evolving faults may happen when the object causing a single line-toground fault touches conductor(s) of additional phase or phases [19].

There have been several articles discussing evolving faults in transmission grid [20-24]. In [20], a few evolving faults recorded by transmission line relays are presented. It is learned from these practical experiences that evolving faults can delay distance element tripping which may result in longer duration of existence of faults. The authors of [21] use the ratio of zero sequence fault current over negative sequence fault current as the criterion to detect evolving faults. Due to evolving fault's changing nature, fault classification is not easy. In [22], the impact of evolving fault on the fault phase selector is analysed, and it is shown that various factors such as fault position and fault resistance could cause incorrect phase selection. The authors of [23] use artificial neural networks (ANN) to select fault phase of evolving faults. Locating evolving faults is less studied compared with stationary faults, and this paper for the first time puts forwards a wide-area evolving fault location method. Reference [19] presents a time-domain method to locate evolving faults in distribution systems This method requires accurate fault classification that is a demanding task itself. Incorrect fault classification would yield erroneous estimation of where the fault happens. In [24], a method based on ANN is designed to locate evolving faults on transmission lines without knowing fault type information, where the network is trained under a variety of possible fault conditions. A method based on wide area measurements for locating faults is provided in [25]. This paper will further develop this approach to deal with evolving faults. 
In order to obviate the dependency on fault classification and find the fault location by using analytical approach, this paper proposes a new fault location algorithm for evolving faults. Changing fault phases would impose little impact on the estimation result. There is no need to detect whether a fault is an evolving fault or not. This method is also immune to fault resistance. In other words, even both the fault phase and fault resistance are not constant, accurate fault location can still be computed. This algorithm is applicable to both single-circuit and double-circuit lines, and is able to deal with both transposed and untransposed cases. Another feature of this method is that it utilizes sparse wide area measurements that do not have to be captured from the ends of the faulted line. Distributed line parameter model is adopted in order to accurately model the line distance transmission line. In practical applications, sparse wide area measurements can be obtained from recording devices installed across the system such as phasor measurement units, digital fault recorders, etc [26, 27]. These measurements are transferred to a central office, based on which the proposed fault location method can be applied to estimate the fault location.

The rest of the paper is organized as follows. Section 2 introduces more backgrounds of evolving faults, including characteristics and causes, and describes the proposed wide-are location method. Evaluation of the proposed algorithm is presented in Section 3. The simulated power system and obtained data are exhibited. In Section 4, the conclusions are drawn.

\section{Proposed fault location algorithm}

\subsection{Characteristic of evolving faults}

Evolving faults are faults where the phases involved change over time [17,24]. The characteristic of an evolving fault is that its faulted phases change over time, while other types of faults' faulted phases remain unchanged. Whether a fault can be referred to as an evolving fault depends on its faulted phase(s), rather than other fault conditions such as fault resistance. For example, a fault with time-dependent fault resistance is not an evolving fault if its faulted phases do not change.

In overhead systems, an evolving fault may happen when a tree limb first touches one, then two or all three phases in succession, making the fault changes from single line-to-ground fault to double line-to-ground fault $[20,24]$. For example, an evolving fault may begin as an AG fault, and changes to ABG fault after a few power cycles. The sample plots of fault voltage and current during an example evolving fault are shown in Figure 1(a) and Figure 1 (b), respectively. The fault initially occurs at as a single line-to-ground fault in phase A, and evolves to a double line-to-ground fault between phases A and B within around four cycles. Typically, the location of the fault would not change during the evolving fault [21]. Evolving faults occur less often than commonly occurring shunt faults. However, in post-fault power networks, evolving faults can easily happen since the systems are under abnormal conditions [19, 21].

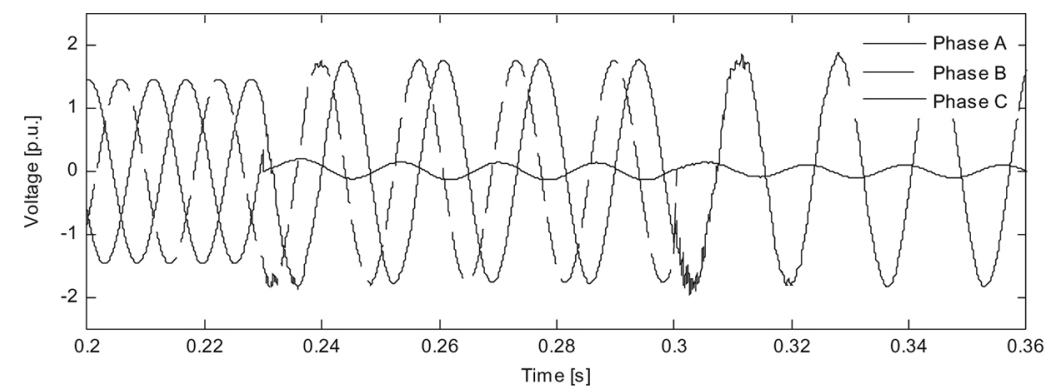

(a)

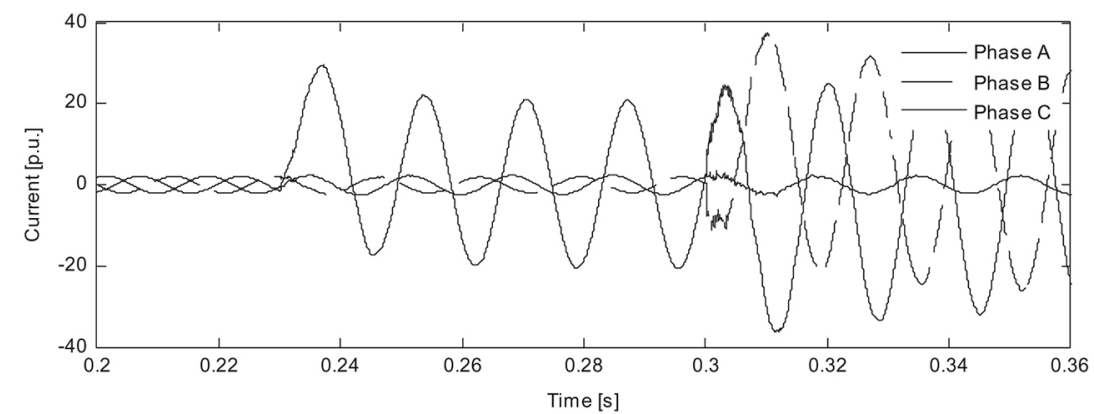

(b)

Figure 1: Waveforms of (a) voltage and (b) current during an example AG-to-ABG evolving fault. 


\subsection{Derivation of fault location}

The method to be presented is based on bus impedance matrix concept [25], and is intended to locate evolving faults on transmission lines. The following part of this section will first discuss the derivation of faulted network's bus impedance matrix, then express the fault current and voltage in terms of fault location, and finally determine the fault location.

Figure 2 presents a section of a power transmission system between buses $p$ and $q$, where the remaining part of the system is not shown. Bus $r$ is added as the fault bus. The following notations are adopted. $n$ is the total number of nodes in the entire transmission system without the fault nodes. $p_{1}, p_{2}, p_{3}, q_{1}, q_{2}$, and $q_{3}$ are the nodes of the sample transmission line. The nodes of the fictitious fault bus are represented by $r_{1}, r_{2}$, and $r_{3}$, where $r_{1}=n+1, r_{2}=n+2, r_{3}=n+3$. The per-unit fault distance from bus $p$ to the fault bus $r$ is denoted as $m . Z_{0}$ is the bus impedance matrix of the pre-fault network in phase domain, while $Z$ is the bus impedance matrix of the during fault network in the phase domain. The element in the $k$ th row and $l$ th column of $Z$ is written as $Z_{k l}$. $z$ and $\boldsymbol{y}$ represent the sample line's per unit length impedance matrix and admittance matrix, respectively.

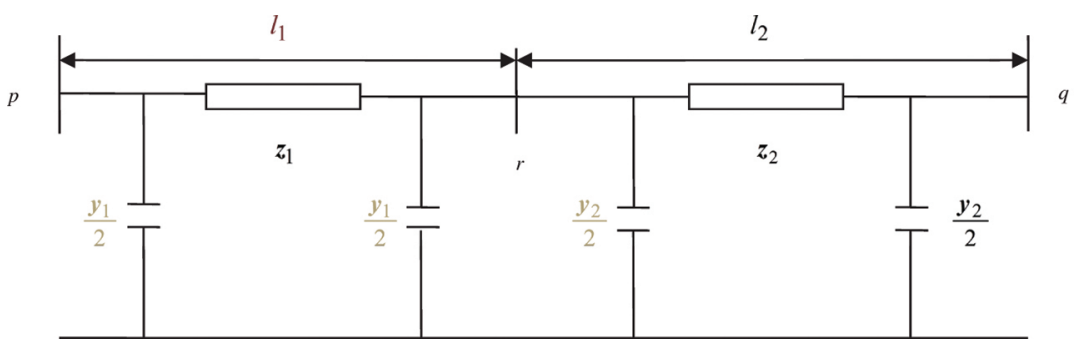

Figure 2: A section of a power transmission system.

The prefault network's bus impedance $\boldsymbol{Z}_{0}$ can be readily developed. The first $n$ rows and first $n$ columns of $Z$ are identical with $Z_{0}$. The other part of $\mathbf{Z}$ includes the driving point impedances of faulted nodes, the transfer impedances between a faulted node and a non-fault node, and the transfer impedances between a fault node and another fault node. These impedances will be derived in the following paragraphs.

Based on the general analysis of multi-phase system, the equivalent Pi circuit parameters of the line between $p$ and $r$ can be derived as functions of $m[28]$ :

$$
z_{1}=z B \operatorname{diag}[\sinh (\boldsymbol{\gamma} m l) \cdot / \gamma] B^{-1}
$$

$$
\boldsymbol{y}_{1} / 2=B \operatorname{diag}[\tanh (\gamma m l / 2) . / \boldsymbol{\gamma}] \boldsymbol{B}^{-1} \boldsymbol{y}
$$

where $B$ is the eigenvector of $y z$; $\operatorname{diag}[$.$] returns a square diagonal matrix with the elements of input vector on$ its diagonal; "./" stands for element-wise division; $\gamma$ is a vector composed of $\gamma_{j}$ which is the square root of the $j$ th eigenvalue of $\boldsymbol{y z} ; j=1,2,3$ for single-circuit lines, and $j=1,2, \ldots, 6$ for double-circuit lines.

It is noted that the parameters derived are phase domain matrices, and thus are applicable to untransposed lines. Similarly, the equivalent Pi circuit parameters for the line between $q$ and $r$ can also be derived as functions of $m$.

Assume $k$ is a measurable non-fault bus in the system, which includes nodes $k_{1}, k_{2}$, and $k_{3}$. The transfer impedance between the node $k_{i}, i=1,2,3$ and the fault nodes can be obtained as

$$
Z_{\boldsymbol{k}_{\boldsymbol{i}} \boldsymbol{r}}=\left(\boldsymbol{y}_{1} / 2+\boldsymbol{y}_{2} / 2+\boldsymbol{z}_{1}^{-1}+\boldsymbol{z}_{2}^{-1}\right)^{-1}\left(\boldsymbol{z}_{1}^{-1} \mathbf{Z}_{\boldsymbol{k}_{\boldsymbol{i}} \boldsymbol{p}}+\boldsymbol{z}_{2}^{-1} \mathbf{Z}_{\boldsymbol{k}_{\boldsymbol{i}} \boldsymbol{q}}\right), \quad i=1,2,3
$$

The driving point impedances and the transfer impedances related to the fault nodes are

$$
\boldsymbol{Z}_{\boldsymbol{r} \boldsymbol{r}_{i}}=\left(\boldsymbol{y}_{1} / 2+\boldsymbol{y}_{2} / 2+\boldsymbol{z}_{1}^{-1}+\boldsymbol{z}_{2}^{-1}\right)^{-1}\left(\boldsymbol{z}_{1}^{-1} \boldsymbol{Z}_{\boldsymbol{p r}}+\boldsymbol{z}_{2}^{-1} \mathbf{Z}_{\boldsymbol{q} \boldsymbol{r}_{i}}+\boldsymbol{u}_{i}\right), \quad i=1,2,3
$$

where $\boldsymbol{u}$ is a three by three identity matrix, whose $i$ th column is denoted by $\boldsymbol{u}_{i}$.

It is seen from eqs (3) and (4) that $Z_{k r}$ and $Z_{r r}$ are both functions of the unknown fault distance $m$, and are independent of the fault resistance and the fault type.

The fault current $I_{f}$ is calculated based on the following equation

$$
I_{f}=-\left(Z_{k r}^{T} Z_{k r}\right)^{-1}\left(Z_{k r}^{T} \Delta E_{k}\right)
$$


where $\Delta E_{k}$ is the superimposed voltage at bus $k$.

The prefault voltages at the fault bus, $E_{r 0}$, can be estimated based on the prefault network conditions. Therefore, the during-fault voltage at the fault bus, $E_{r}$, is obtained as

$$
E_{r}=E_{r 0}-Z_{r r} I_{f}
$$

Based on $I_{f}$ and $E_{r}$, the reactive power consumed by the fault resistance can be computed as

$$
Q=\operatorname{Imag}\left\{-E_{r}\left[\left(\boldsymbol{Z}_{\boldsymbol{k r}}{ }^{\mathrm{T}} \boldsymbol{Z}_{\boldsymbol{k} r}\right)^{-1}\left(\boldsymbol{Z}_{\boldsymbol{k} r}{ }^{\mathrm{T}} \Delta \boldsymbol{E}_{\boldsymbol{k}}\right)\right]^{*}\right\}
$$

where Imag \{.\} returns the imaginary part of its argument, and $(.)^{*}$ denotes the complex conjugate. It can be observed that $m$ is the only unknown variable in eq. (7). Since the fault resistance only consumes real power, eq. (7) should equal to zero. The fault location $m$ can then be solved by the Newton-Raphson technique.

This approach is applicable when measurements from one bus are available. When measurements from two buses are available, an alternative method is derived in the following subsection.

\subsection{Cases when measurements from two buses are available}

A two-bus algorithm can be implemented when measurements from two buses are available. Suppose voltage measurements are available from non-fault buses $k$ and $k^{\prime}$, and the measurements are synchronised. It can be derived that

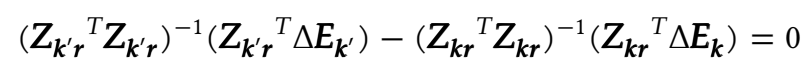

Equation (8) only includes one unknown variable, $m$. Thus, the fault location can be derived.

If the measurements at bus $k$ and $k^{\prime}$ are not synchronised, by equalling the magnitudes of the fault current derived based on the two sets of measurements, the fault location can still be obtained. The fault current calculated based on measurements from bus $k$ is $-\left(Z_{k r}{ }^{T} Z_{k r}\right)^{-1}\left(Z_{k r}{ }^{T} \Delta E_{k}\right)$, and the value based on measurements from bus $k^{\prime}$ is $-\left(Z_{\boldsymbol{k}^{\prime} r}^{T} \boldsymbol{Z}_{\boldsymbol{k}^{\prime} r}\right)^{-1}\left(\boldsymbol{Z}_{\boldsymbol{k}^{\prime} r}{ }^{T} \Delta \boldsymbol{E}_{\boldsymbol{k}^{\prime}}\right)$ Equaling their magnitude yields

$$
\left|\left(Z_{k r}^{T} Z_{k r}\right)^{-1}\left(Z_{k r}^{T} \Delta E_{k}\right)\right|-\left|\left(Z_{k^{\prime} r}^{T} Z_{k^{\prime} r}\right)^{-1}\left(Z_{k^{\prime} r}^{T} \Delta E_{k^{\prime}}\right)\right|=0
$$

where |.| returns magnitude of its argument. The fault location can be obtained by solving eq. (9).

\subsection{Cases when the faulted line is a double-circuit line}

When the faulted line is a double-circuit line, a fictitious bus $r$ containing six nodes are added to the network. Bus $r$ is at the assumed fault location. The equivalent Pi circuit line parameters can be calculated following eqs (1)-(2). It is noted that $\boldsymbol{z}_{1}, \boldsymbol{y}_{1}, \boldsymbol{z}_{2}, \boldsymbol{y}_{2}$ are six by six matrices in the case of double-circuit line. The transfer impedances between nodes on bus $k$ and the faulted nodes can be derived as

$$
Z_{k_{i} r}=\left(\boldsymbol{y}_{1} / 2+\boldsymbol{y}_{2} / 2+\boldsymbol{z}_{1}^{-1}+\boldsymbol{z}_{2}^{-1}\right)^{-1}\left(\boldsymbol{z}_{1}^{-1}\left[Z_{\boldsymbol{k}_{i} \boldsymbol{p}}, \boldsymbol{Z}_{\boldsymbol{k}_{\boldsymbol{i}} \boldsymbol{p}}\right]^{T}+\boldsymbol{z}_{2}^{-1}\left[\boldsymbol{Z}_{\boldsymbol{k}_{\boldsymbol{i}} \boldsymbol{q}} \boldsymbol{Z}_{\boldsymbol{k}_{\boldsymbol{i}}}\right]^{T}\right), \quad i=1,2, \ldots, 6
$$

The transfer impedances and the driving point impedances related to the faulted nodes are expressed as

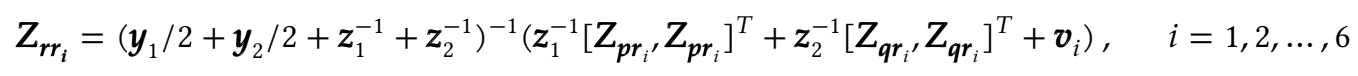

where $Z_{p r_{i}}$ and $Z_{q r_{i}}$ can be calculated based on eq. (10), and $v$ is a six by six identity matrix whose $i$ th column is denoted as $\boldsymbol{v}_{i}$.

The prefault voltage at bus $r$ is

$$
\boldsymbol{E}_{\boldsymbol{r} 0}=\left(\boldsymbol{y}_{1} / 2+\boldsymbol{y}_{2} / 2+\boldsymbol{z}_{1}^{-1}+\boldsymbol{z}_{2}^{-1}\right)^{-1}\left(\boldsymbol{z}_{1}^{-1}\left[\boldsymbol{E}_{\boldsymbol{p} 0}, \boldsymbol{E}_{\boldsymbol{p} 0}\right]^{T}+\boldsymbol{z}_{2}^{-1}\left[\boldsymbol{E}_{\boldsymbol{q} 0}, \boldsymbol{E}_{\boldsymbol{q} 0}\right]^{T}\right)
$$

The during-fault voltage at bus $r$ and the fault current $I_{f}$ are calculated following eqs (6) and (5). The fault location can then be solved based on eq. (7). When measurements from two buses are available, eq. (8) can be adopted to derive the fault location. 


\section{Evaluation studies}

The presented fault-location algorithm has been validated by using the Electromagnetic Transients Program (EMTP) simulation data of faults in a 27-bus, $345-\mathrm{kV}, 60 \mathrm{~Hz}$ transmission system. The diagram of the studied system is shown in Figure 3 [25]. The bus numbers are labelled, and the line lengths in miles are given in parenthesis. Matlab is utilized to implement the proposed methods. The estimation accuracy is measured by the percentage error as

$$
\% \text { Error }=\frac{\mid \text { ActualLocation }- \text { EsimationLocation } \mid}{\text { TotalLengthofFaultedLine }} \times 100
$$

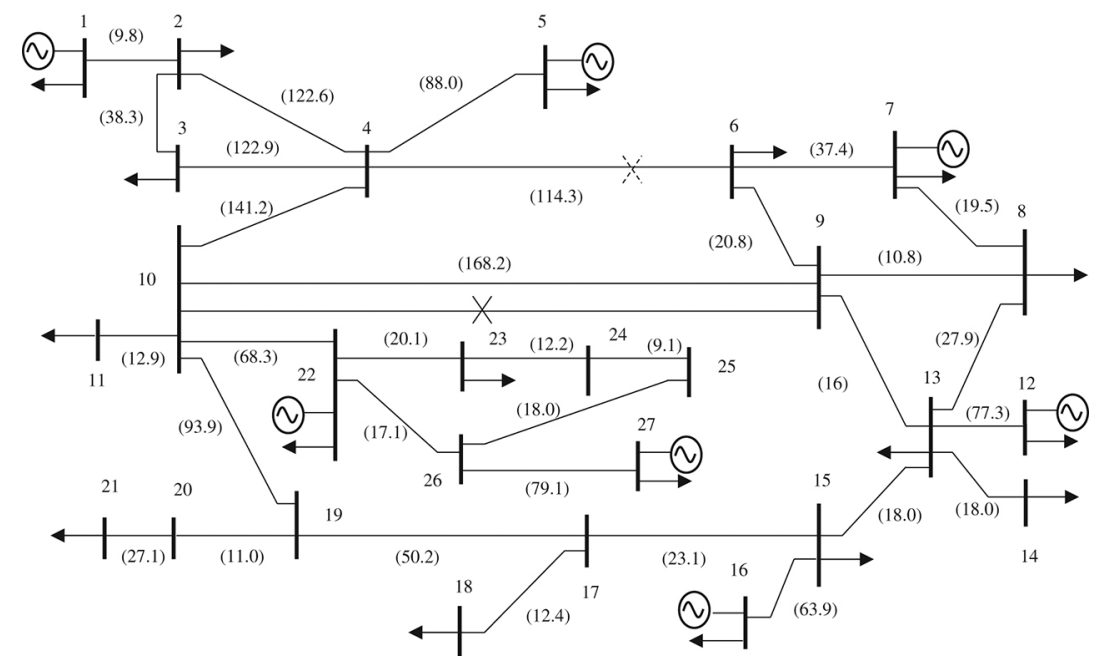

Figure 3: Diagram of the studied system.

\subsection{Fault location results by two-bus algorithm}

For single-circuit line fault location study, the evolving fault is assumed to happen on the line between bus 4 and bus 6 , and is labelled by dashed cross in Figure 3. For double-circuit line fault location study, the evolving fault is imposed on the untransposed line between bus 9 and bus 10, and is denoted by solid cross in Figure 3 . An example case study will be demonstrated below, followed by the evaluation under various conditions.

An AG fault occurs on the single-circuit line, 34.3 miles, i. e. 0.3 p.u., away from bus 4 , and evolves to an ABG fault after $35 \mathrm{~ms}$. Voltage measurements are available at two buses: bus 5 and bus 8 . The three phase transient voltages observed at bus 5 and bus 8 are shown in Figure 4 .
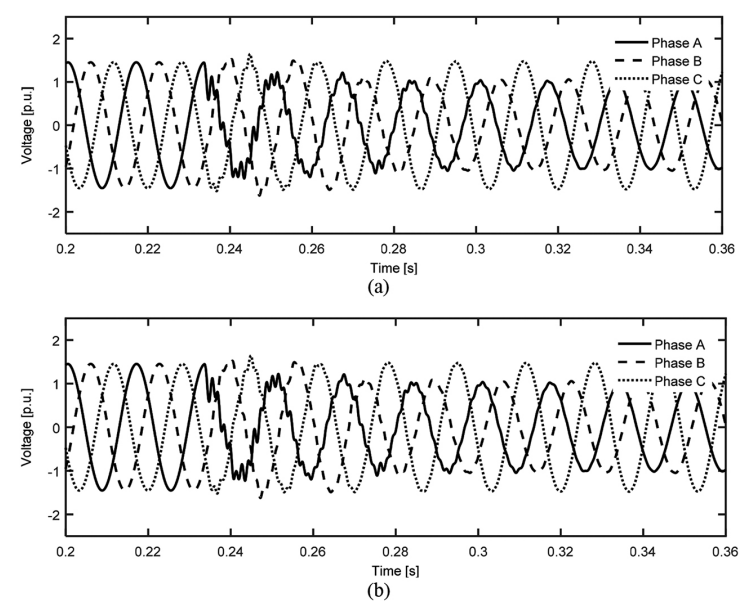

Figure 4: Voltage measurements at (a) bus 5 and (b) bus 8 during an AG-to-ABG evolving fault.

Now, the two-bus fault location algorithm developed in Section 2 is applied to estimate the fault location. The locus of estimated fault location versus time is drawn in Figure 5. It can be observed that due to changing 
fault types and transients, the estimated fault location locus fluctuates at the beginning, and then levels off at 0.3 p.u. which is the actual fault location. The locus indicates a quick convergence of the proposed fault location method. It is noted that the same fault location method is applied without the need of fault type identification.

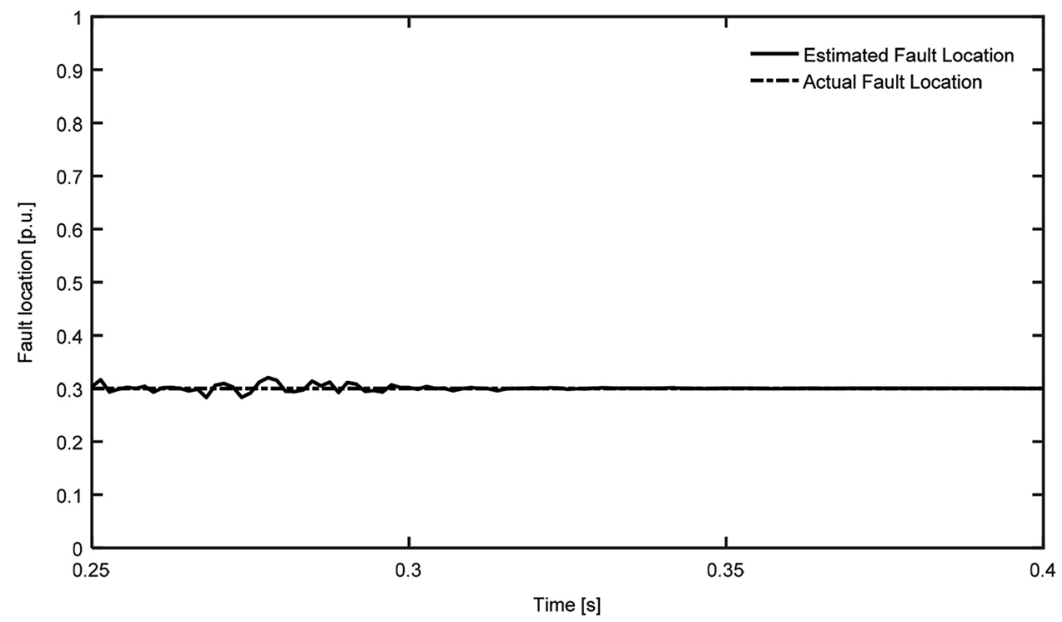

Figure 5: Locus of estimated fault location for an AG-to-ABG evolving fault.

For the purpose of evaluating the proposed algorithm's feasibility, different evolving faults under various conditions have been studied.

Table 1 presents the representative conditions of the evolving faults on the single-circuit line and corresponding fault location results. In the table, the first two columns list the fault type information. The fault resistance values for the initial and secondary faults are given in column three and four. The fault location is the distance from bus 4 to the fault, and is presented in column five. The time intervals between the initial and secondary faults are given in column six, and they are chosen below three cycles. The percentage errors of estimations by using measurements from two buses are shown in the last three columns in Table 1 . The voltage measurements from buses $5 \& 8$ and $7 \& 22$ are considered as synchronised and the measurements from bus $12 \& 24$ are unsynchronised. The secondary faults may differ from the initial fault in terms of fault type or fault resistance or both. It can be observed that quite accurate fault location results are achieved, regardless of these changes.

Table 1: Single-circuit line evolving fault location results using two-bus algorithm.

\begin{tabular}{|c|c|c|c|c|c|c|c|c|}
\hline \multirow{2}{*}{$\begin{array}{l}\text { Initial } \\
\text { fault } \\
\text { type }\end{array}$} & \multirow{2}{*}{$\begin{array}{l}\text { Sec- } \\
\text { ondary } \\
\text { fault } \\
\text { type }\end{array}$} & \multirow{2}{*}{$\begin{array}{l}\text { Initial } \\
\text { fault res. } \\
(\Omega)\end{array}$} & \multirow[t]{2}{*}{$\begin{array}{l}\text { Secondary } \\
\text { fault res. }(\Omega)\end{array}$} & \multirow[t]{2}{*}{$\begin{array}{l}\text { Fault loca. } \\
\text { (p.u.) }\end{array}$} & \multirow[t]{2}{*}{$\begin{array}{l}\text { Time in- } \\
\text { terval (ms) }\end{array}$} & \multicolumn{3}{|c|}{$\begin{array}{l}\text { Est. error }(\%) \text { using } \\
\text { measurements from buses }\end{array}$} \\
\hline & & & & & & $\begin{array}{l}5 \& 8 \\
\text { (syn.) }\end{array}$ & $\begin{array}{l}7 \& 22 \\
\text { (syn.) }\end{array}$ & $\begin{array}{l}\text { 12\&24 } \\
\text { (unsyn.) }\end{array}$ \\
\hline AG & $\mathrm{AG}$ & 10 & 1 & 0.8 & 15 & 0.06 & 0.14 & 0.12 \\
\hline AG & ABG & 10 & 10 & 0.3 & 10 & 0.03 & 0.07 & 0.19 \\
\hline AG & ABCG & 5 & 5 & 0.4 & 26 & 0.02 & 0.05 & 0.17 \\
\hline BG & BCG & 15 & 5 & 0.5 & 26 & 0.01 & 0.18 & 0.14 \\
\hline BG & ABCG & 20 & 15 & 0.5 & 10 & 0.01 & 0.16 & 0.11 \\
\hline $\mathrm{AB}$ & ABG & 10 & 5 & 0.3 & 8 & 0.03 & 0.10 & 0.18 \\
\hline BC & ABCG & 1 & 1 & 0.7 & 17 & 0.01 & 0.16 & 0.12 \\
\hline BC & BCG & 50 & 50 & 0.5 & 17 & 0.09 & 0.21 & 0.22 \\
\hline $\mathrm{BC}$ & $\mathrm{ABC}$ & 10 & 10 & 0.2 & 30 & 0.01 & 0.05 & 0.09 \\
\hline
\end{tabular}

In Table 2, columns 1-6 are initial fault type, secondary fault type, initial fault resistance, secondary fault resistance, actual fault location and the time interval between faults. It is seen that the developed algorithm works well with double-circuit lines. By using synchronised measurements from buses $7 \& 12$ and unsynchronised measurements from $15 \& 22$ and $19 \& 26$, accurate estimates are produced.

Table 2: Double-circuit line evolving fault location results using two-bus algorithm.

\begin{tabular}{|c|c|c|c|c|c|c|}
\hline $\begin{array}{l}\text { Initial } \\
\text { fault } \\
\text { type }\end{array}$ & $\begin{array}{l}\text { Second. fault } \\
\text { type }\end{array}$ & $\begin{array}{l}\text { Initial } \\
\text { fault } \\
\text { res. } \\
(\Omega)\end{array}$ & $\begin{array}{l}\text { Sec- } \\
\text { ond. } \\
\text { fault } \\
\text { res. } \\
(\Omega)\end{array}$ & $\begin{array}{l}\text { Fault loca. } \\
\text { (p.u.) }\end{array}$ & $\begin{array}{l}\text { Time } \\
\text { inter- } \\
\text { val } \\
\text { (ms) }\end{array}$ & $\begin{array}{l}\text { Est. error (\%) using measurements from } \\
\text { buses } \\
\text { Brought to you by | University of Kentucky } \\
\text { Authenticated } \\
\text { Download Date |11/12/18 9:30 PM }\end{array}$ \\
\hline
\end{tabular}




\begin{tabular}{lllllllll} 
& & & & & & $\mathbf{7 \& 1 2}$ (syn.) & $\begin{array}{l}\text { 15\&22 } \\
\text { (unsyn.) }\end{array}$ & $\begin{array}{l}\text { 19\&26 } \\
\text { (unsyn.) }\end{array}$ \\
\hline AG & AG & 5 & 1 & 0.5 & 33 & 0.04 & 0.10 & 0.11 \\
AG & ABG & 10 & 5 & 0.7 & 20 & 0.06 & 0.09 & 0.09 \\
AG & ABCG & 50 & 50 & 0.7 & 20 & 0.04 & 0.35 & 0.41 \\
BG & BCG & 5 & 5 & 0.3 & 28 & 0.05 & 0.09 & 0.09 \\
BG & ABCG & 15 & 15 & 0.6 & 15 & 0.05 & 0.10 & 0.12 \\
AB & ABG & 5 & 1 & 0.3 & 25 & 0.02 & 0.09 & 0.09 \\
BC & BCG & 15 & 15 & 0.7 & 30 & 0.04 & 0.06 & 0.07 \\
BC & ABC & 5 & 5 & 0.8 & 15 & 0.06 & 0.07 & 0.11 \\
BC & ABCG & 20 & 20 & 0.2 & 10 & 0.23 & 0.26 & 0.31 \\
\hline
\end{tabular}

\subsection{Fault location results by one-bus algorithm}

An example evolving fault is assumed to evolve from BG fault to ABCG fault $8 \mathrm{~ms}$ after the initial fault. The fault occurs on the double-circuit untransposed line between bus 9 and bus 10 . The fault resistance is 5 ohms. Figure 6 depicts the voltage measurement from bus 11.

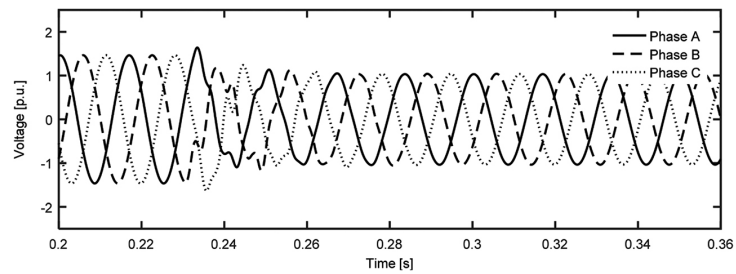

Figure 6: Voltage measurements at bus 11 during a BG-to-ABCG evolving fault.

The fault location estimation locus is drawn in Figure 7. The estimation locus first oscillates around the red reference line that represents the actual fault location. Afterwards, the estimation locus and the reference line coincide with each other. In other words, quite accurate estimation is achieved quickly.

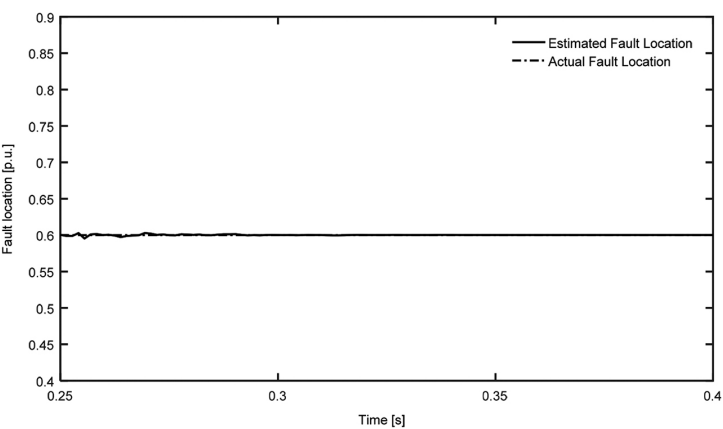

Figure 7: Locus of estimated fault location for a BG-to-ABCG evolving fault.

Similarly, different evolving faults are utilized to validate the proposed method. The following section exhibits the percentage fault location errors for one-bus algorithm. Evolving faults happening on both singlecircuit and double-circuit lines are included in the study. Extensive fault conditions have been tested, and representative results are provided here.

In Table 3 and Table 4, the columns 1-6 are the initial fault type, secondary fault type, initial fault resistance, secondary fault resistance, actual fault location, and the time interval. The other columns are the fault location estimation errors. It is shown that the proposed method has achieved quite accurate results.

Table 3: Single-circuit line evolving fault location results using one-bus algorithm.

\begin{tabular}{|c|c|c|c|c|c|c|c|c|}
\hline \multirow{2}{*}{$\begin{array}{l}\text { Initial } \\
\text { fault } \\
\text { type }\end{array}$} & \multirow[t]{2}{*}{$\begin{array}{l}\text { Secondary } \\
\text { fault type }\end{array}$} & \multirow{2}{*}{$\begin{array}{l}\text { Initial } \\
\text { fault res. } \\
(\Omega)\end{array}$} & \multirow[t]{2}{*}{$\begin{array}{l}\text { Secondary } \\
\text { fault res. }(\Omega)\end{array}$} & \multirow{2}{*}{$\begin{array}{l}\text { Fault } \\
\text { loca. } \\
\text { (p.u.) }\end{array}$} & \multirow[t]{2}{*}{$\begin{array}{l}\text { Time inter- } \\
\text { val (ms) }\end{array}$} & \multicolumn{3}{|c|}{$\begin{array}{l}\text { Est. error }(\%) \text { using } \\
\text { measurements from buses }\end{array}$} \\
\hline & & & & & & 3 & 12 & 22 \\
\hline AG & $\mathrm{AG}$ & 5 & 15 & 0.2 & 9 & 0.19 & 0.11 & 0.21 \\
\hline AG & $\mathrm{ABG}$ & 10 & 5 & 0.5 & 10 & 0.12 & 0.04 & 0.32 \\
\hline
\end{tabular}




\begin{tabular}{lllllllll} 
AG & ABCG & 5 & 5 & 0.3 & 26 & 0.03 & 0.03 & 0.05 \\
BG & BCG & 10 & 15 & 0.7 & 26 & 0.12 & 0.04 & 0.33 \\
BG & ABCG & 10 & 10 & 0.6 & 15 & 0.01 & 0.05 & 0.03 \\
AB & ABG & 50 & 50 & 0.8 & 10 & 0.05 & 0.04 & 0.04 \\
BC & ABCG & 10 & 1 & 0.5 & 17 & 0.02 & 0.01 & 0.03 \\
BC & BCG & 15 & 15 & 0.6 & 17 & 0.15 & 0.07 & 0.29 \\
BC & ABC & 5 & 5 & 0.8 & 30 & 0.03 & 0.02 & 0.02 \\
\hline
\end{tabular}

Table 4: Double-circuit line evolving fault location results using one-bus algorithm.

\begin{tabular}{|c|c|c|c|c|c|c|c|c|}
\hline \multirow{2}{*}{$\begin{array}{l}\text { Initial } \\
\text { fault } \\
\text { type }\end{array}$} & \multirow[t]{2}{*}{$\begin{array}{l}\text { Secondary } \\
\text { fault type }\end{array}$} & \multirow{2}{*}{$\begin{array}{l}\text { Initial } \\
\text { fault res. } \\
(\Omega)\end{array}$} & \multirow[t]{2}{*}{$\begin{array}{l}\text { Secondary } \\
\text { fault res. }(\Omega)\end{array}$} & \multirow{2}{*}{$\begin{array}{l}\text { Fault } \\
\text { loca. } \\
\text { (p.u.) }\end{array}$} & \multirow[t]{2}{*}{$\begin{array}{l}\text { Time inter- } \\
\text { val (ms) }\end{array}$} & \multicolumn{3}{|c|}{$\begin{array}{l}\text { Est. error }(\%) \text { using } \\
\text { measurements from buses }\end{array}$} \\
\hline & & & & & & 11 & 19 & 21 \\
\hline AG & $\mathrm{AG}$ & 1 & 10 & 0.3 & 10 & 0.15 & 0.12 & 0.11 \\
\hline $\mathrm{AG}$ & ABG & 20 & 10 & 0.8 & 10 & 0.05 & 0.06 & 0.08 \\
\hline AG & ABCG & 5 & 5 & 0.3 & 26 & 0.02 & 0.04 & 0.12 \\
\hline BG & BCG & 15 & 5 & 0.6 & 26 & 0.05 & 0.08 & 0.09 \\
\hline BG & $\mathrm{ABCG}$ & 5 & 15 & 0.6 & 8 & 0.05 & 0.22 & 0.09 \\
\hline$A B$ & ABG & 10 & 1 & 0.3 & 30 & 0.08 & 0.05 & 0.09 \\
\hline $\mathrm{BC}$ & $\mathrm{ABCG}$ & 5 & 5 & 0.7 & 17 & 0.03 & 0.19 & 0.06 \\
\hline BC & BCG & 10 & 10 & 0.5 & 17 & 0.05 & 0.08 & 0.04 \\
\hline $\mathrm{BC}$ & $\mathrm{ABC}$ & 15 & 15 & 0.2 & 30 & 0.02 & 0.05 & 0.15 \\
\hline
\end{tabular}

\subsection{Discussion}

The proposed fault location method uses voltage phasors to calculate the fault location. So accuracy of phasor estimation will affect the accuracy of fault location. This paper uses Fourier transform method to extract phasors. For improved accuracy, advanced phasor extraction method such as least squares based approach may be used to extract phasors [29]. This paper focuses on the fault location method and hence does not detail phasor extraction methods. However, impact of measurement noises or phasor estimation error on the proposed fault location method is examined below.

To simulate measurement noises, $1 \%$ error is added to the voltage measurements and then the fault location method is applied. The fault location results are listed in Table 5. It is shown that the fault location estimation s still quite accurate.

Table 5: Fault location results based on noisy measurements.

\begin{tabular}{|c|c|c|c|c|c|c|c|c|c|}
\hline \multirow{2}{*}{$\begin{array}{l}\text { Initial } \\
\text { fault } \\
\text { type }\end{array}$} & \multirow{2}{*}{$\begin{array}{l}\text { Second. } \\
\text { fault } \\
\text { type }\end{array}$} & \multirow{2}{*}{$\begin{array}{l}\text { Initial } \\
\text { fault res. } \\
(\Omega)\end{array}$} & \multirow{2}{*}{$\begin{array}{l}\text { Second. } \\
\text { fault res. } \\
(\Omega)\end{array}$} & \multirow{2}{*}{$\begin{array}{l}\text { Fault } \\
\text { loca. } \\
\text { (p.u.) }\end{array}$} & \multirow{2}{*}{$\begin{array}{l}\text { Time } \\
\text { interval } \\
\text { (ms) }\end{array}$} & \multirow{2}{*}{$\begin{array}{l}\text { Faulted } \\
\text { line cir- } \\
\text { cuit }\end{array}$} & \multicolumn{3}{|c|}{$\begin{array}{l}\text { Est. error }(\%) \text { using } \\
\text { measurements from buses }\end{array}$} \\
\hline & & & & & & & $3 \& 11$ & 15 & 19 \\
\hline AG & $\mathrm{AG}$ & 1 & 10 & 0.3 & 21 & Single & 0.44 & 0.43 & 0.33 \\
\hline AG & $\mathrm{ABG}$ & 20 & 10 & 0.8 & 32 & Single & 0.67 & 0.51 & 0.49 \\
\hline AG & $\mathrm{ABCG}$ & 5 & 5 & 0.3 & 42 & Double & 0.34 & 0.80 & 0.47 \\
\hline BG & BCG & 15 & 5 & 0.6 & 12 & Double & 0.95 & 0.74 & 0.65 \\
\hline BG & ABCG & 5 & 15 & 0.6 & 28 & Single & 0.70 & 0.84 & 0.46 \\
\hline $\mathrm{AB}$ & ABG & 10 & 1 & 0.3 & 13 & Single & 0.30 & 0.67 & 0.68 \\
\hline $\mathrm{BC}$ & ABCG & 5 & 5 & 0.7 & 35 & Double & 0.77 & 0.53 & 0.65 \\
\hline $\mathrm{BC}$ & BCG & 10 & 10 & 0.5 & 2 & Double & 0.46 & 0.41 & 0.30 \\
\hline
\end{tabular}

It is also noted that since the proposed method is applicable regardless of the fault type, a fault location locus versus time can be achieved. Using the obtained fault location, other fault conditions including the fault type versus time can be further derived. Thus, we will have a better understanding of the faulted system, and be more confident about the obtained fault location than if we only have one single fault location obtained using the last cycle of the waveforms. 


\section{Conclusion}

The fault phases in an evolving fault change during the fault. Fault location methods that depend on fault type information may give unreliable results if incorrect fault type is obtained. This paper presents a method to locate evolving faults that is applicable regardless of time varying fault conditions. Neither fault type information nor fault resistance is a prerequisite for this algorithm. By using sparse wide area measurements, quite accurate estimation can be obtained even when the measurements are not available from the terminals of the faulted lines. This method is applicable to both single-circuit and double-circuit lines, and fully considers the shunt capacitance of the transmission lines. Evaluation studies have demonstrated that the proposed methods yield quite accurate results.

\section{Appendix}

This section provides the model data of the studied 27-bus system. The per-unit system is based on a based voltage of $345 \mathrm{kV}$ and base volt-ampere of 100MVA. The transmission line data, generator data, and load data are listed in Table 6-Table 9.

Table 6: Transmission line data excluding the double-circuit line.

\begin{tabular}{|c|c|c|c|c|c|c|c|c|}
\hline $\begin{array}{l}\text { Fron } \\
\text { Bus }\end{array}$ & $\begin{array}{l}\text { nfo } \\
\text { Bus }\end{array}$ & $\begin{array}{l}\text { Length } \\
\text { (mile) }\end{array}$ & R1(p.u.) & X1(p.u.) & B1(p.u.) & R0(p.u.) & X0(p.u.) & B0(p.u.) \\
\hline 1 & 2 & 9.8 & 0.00054 & 0.00498 & 0.08169 & 0.00162 & 0.01494 & 0.04084 \\
\hline 2 & 3 & 38.3 & 0.00214 & 0.01929 & 0.32695 & 0.00642 & 0.05787 & 0.16348 \\
\hline 2 & 4 & 122.6 & 0.00667 & 0.06199 & 1.03274 & 0.04906 & 0.1542 & 0.613 \\
\hline 3 & 4 & 122.9 & 0.0068 & 0.06255 & 1.03066 & 0.04913 & 0.155 & 0.6145 \\
\hline 4 & 5 & 88 & 0.00484 & 0.04472 & 0.73934 & 0.03108 & 0.1028 & 0.44 \\
\hline 4 & 6 & 114.3 & 0.00633 & 0.05754 & 0.97111 & 0.0557 & 0.1832 & 0.5715 \\
\hline 4 & 10 & 141.2 & 0.0077 & 0.0717 & 1.1612 & 0.0572 & 0.1779 & 0.79229 \\
\hline 6 & 7 & 37.4 & 0.00166 & 0.01852 & 0.32361 & 0.00498 & 0.05556 & 0.16181 \\
\hline 6 & 9 & 20.8 & 0.00075 & 0.01014 & 0.18298 & 0.0095 & 0.0352 & 0.104 \\
\hline 7 & 8 & 19.5 & 0.0009 & 0.00959 & 0.17028 & 0.0073 & 0.0243 & 0.0975 \\
\hline 8 & 9 & 10.8 & 0.00048 & 0.00536 & 0.09336 & 0.0042 & 0.0196 & 0.054 \\
\hline 8 & 13 & 27.9 & 0.00151 & 0.01378 & 0.24124 & 0.0079 & 0.0527 & 0.1395 \\
\hline 9 & 13 & 16 & 0.00087 & 0.00793 & 0.13882 & 0.0046 & 0.0303 & 0.08 \\
\hline 10 & 11 & 12.9 & 0.0008 & 0.0077 & 0.1237 & 0.00542 & 0.01682 & 0.0645 \\
\hline 10 & 19 & 93.9 & 0.00513 & 0.04479 & 0.83974 & 0.0348 & 0.1706 & 0.4695 \\
\hline 10 & 22 & 68.3 & 0.0035 & 0.03436 & 0.58279 & 0.02428 & 0.09307 & 0.36804 \\
\hline 12 & 13 & 76 & 0.0042 & 0.0371 & 0.65336 & 0.0126 & 0.1113 & 0.32668 \\
\hline 13 & 14 & 18 & 0.001 & 0.0089 & 0.1523 & 0.003 & 0.0267 & 0.07615 \\
\hline 13 & 15 & 18 & 0.001 & 0.0089 & 0.1523 & 0.003 & 0.0267 & 0.07615 \\
\hline 15 & 16 & 63.9 & 0.0034 & 0.0317 & 0.5398 & 0.0102 & 0.0951 & 0.2699 \\
\hline 15 & 17 & 23.1 & 0.0012 & 0.0111 & 0.1999 & 0.0036 & 0.0333 & 0.09995 \\
\hline 17 & 18 & 12.4 & 0.00066 & 0.00596 & 0.10713 & 0.00198 & 0.01788 & 0.05356 \\
\hline 17 & 19 & 50.2 & 0.00294 & 0.02484 & 0.43528 & 0.01914 & 0.08901 & 0.251 \\
\hline 19 & 20 & 11 & 0.00064 & 0.00543 & 0.09518 & 0.0042 & 0.0195 & 0.055 \\
\hline 20 & 21 & 27.1 & 0.0015 & 0.0134 & 0.2293 & 0.0045 & 0.0402 & 0.11465 \\
\hline 22 & 23 & 20.1 & 0.00042 & 0.00969 & 0.1822 & 0.0066 & 0.02668 & 0.12114 \\
\hline 22 & 26 & 17.1 & 0.00083 & 0.00825 & 0.15134 & 0.00527 & 0.02517 & 0.08945 \\
\hline 23 & 24 & 12.2 & 0.00026 & 0.00584 & 0.11141 & 0.00384 & 0.01727 & 0.07131 \\
\hline 24 & 25 & 9.1 & 0.00044 & 0.00455 & 0.07723 & 0.0029 & 0.01311 & 0.04554 \\
\hline 25 & 26 & 18 & 0.00037 & 0.00864 & 0.16156 & 0.005 & 0.02638 & 0.09106 \\
\hline 26 & 27 & 79.1 & 0.00374 & 0.03812 & 0.69902 & 0.02414 & 0.11857 & 0.41408 \\
\hline
\end{tabular}

In Table 6, the first two columns are the two bus numbers for each branch. The per-unit positive-sequence resistance, positive-sequence reactance, positive-sequence susceptance, zero-sequence resistance, zero-sequence reactance, and zero-sequence susceptance for each branch excluding the untransposed double-circuit line are listed. 
Since the transmission line between bus 9 and bus 10 is untransposed double-circuit lines, there are six modes involved to represent this line, and the modal values used to simulate such line is listed in Table 7.

Table 7: Transmission line data for the line between bus 9 and bus 10 .

\begin{tabular}{ll}
\hline Modes & Modal values of the untransposed double-circuit line \\
\hline 1 & $0.000472451729722+0.003011594685278 \mathrm{j}$ \\
2 & $0.000074001058003+0.000783717824966 \mathrm{j}$ \\
3 & $0.000057640900543+0.000519020785647 \mathrm{j}$ \\
4 & $0.000045966799966+0.000506206323198 \mathrm{j}$ \\
5 & $0.000040415648413+0.000476514356441 \mathrm{j}$ \\
6 & $0.000037474354557+0.000480355357462 \mathrm{j}$ \\
\hline
\end{tabular}

In Table 8, the first column represents the bus number that the generator is connected to. Columns $2-5$ show the zero-sequence source resistance, zero-sequence source reactance, positive-sequence source resistance, and positive-sequence source reactance.

Table 8: Generator data of the power system.

\begin{tabular}{lllll}
\hline $\begin{array}{l}\text { Bus } \\
\text { No. }\end{array}$ & R0(p.u.) & X0(p.u.) & R1(p.u.) & X1(p.u.) \\
\hline 1 & $0.00332,695$ & 0.01794547 & 0.00306751 & 0.0158382 \\
5 & 0.00188591 & 0.05335358 & 0.00236455 & 0.0486705 \\
7 & 0.00592615 & 0.02806461 & 0.01679126 & 0.0407814 \\
12 & 0.00604318 & 0.06398748 & 0.00671002 & 0.0525554 \\
16 & 0.00424012 & 0.02669784 & 0.00925217 & 0.030113 \\
22 & 0.00359328 & 0.02391867 & 0.0005041 & 0.0349924 \\
27 & 0.00635514 & 0.03437664 & 0.00376854 & 0.0195658 \\
\hline
\end{tabular}

Table 9: Load data of the power system.

\begin{tabular}{|c|c|}
\hline Bus No. & Load Impedance (p.u.) \\
\hline 1 & $1.225+0.2487 j$ \\
\hline 2 & $3.1+1.2252 j$ \\
\hline 3 & $1.65+0.235 j$ \\
\hline 5 & $2.425+0.6078 j$ \\
\hline 6 & $0.845+0.3314 j$ \\
\hline 7 & $3.19+0.9779 j$ \\
\hline 8 & $1.056+0.3469 j$ \\
\hline 11 & $1.92+0.56 j$ \\
\hline 12 & $0.648+0.1567 j$ \\
\hline 13 & $4.85+1.2155 j$ \\
\hline 14 & $3.28+0.5939 j$ \\
\hline 15 & $3.28+0.5939 j$ \\
\hline 16 & $0.64+0.1867 j$ \\
\hline 18 & $1.96+0.398 j$ \\
\hline 21 & $2.475+0.3527 j$ \\
\hline 22 & $1.0722+0.2914 j$ \\
\hline 23 & $1.3857+0.3473 \mathrm{j}$ \\
\hline 27 & $1.056+0.3469 j$ \\
\hline
\end{tabular}

In Table 9, the first column represents the bus number that the load is connected to. The second column exhibits the equivalent load impedance in per unit. 


\section{References}

[1] Kezunovic M, Perunicic B. Fault location. In: Webster ], editors. Wiley encyclopedia of electrical and electronics terminology. vol. 7. New York: Wiley, 1999: 276-85.

[2] Saha MM, Izykowski ], Rosolowski E. Fault location on power networks. London: Springer-Verlag London Ltd, 2010.

[3] Popov M, Parmar S, Rietveld G, Preston G, Radojev Z, Terzija V. Methodology for testing a parameter-free fault locator for transmission lines. Electric Power Syst Res. 2016;136(1):92-98.

[4] Liao Y. Fault location utilizing unsynchronized voltage measurements during fault. Electric Power Components Syst. 2006;34(12):1283-93.

[5] Davoudi M, Sadeh ], Kanyab E. Parameter-free fault location for transmission lines based on optimisation. IET Gen Transm Distrib. 2015;9(11):1061-68.

[6] Liang Y, Wang G, Li H. Time-domain fault-location method on HVDC transmission lines under unsynchronized two-end measurement and uncertain line parameters. IEEE Power Delivery. 2015;30(3):1031-38.

[7] Izykowski ], Rosolowski E, Balcerek P, Fulczyk M, Saha M. Fault location on double circuit series-compensated lines using two-end unsynchronized measurements. IEEE Trans Power Delivery. 2011;26(4):2072-80.

[8] Izykowski ], Rosolowski E, Saha MM. Locating faults in parallel transmission lines under availability of complete measurements at one end. IEE Proc Cen Transm Distrib. 2004;151(2):268-73.

[9] Kawady T, Stenzel ]. A practical fault location approach for double circuit transmission lines using single end data. IEEE Trans Power Delivery. 2003;18(4):1166-73.

[10] Zhang Q, Zhang Y, Song W, Yu Y, Wang Z. Fault location of two-parallel transmission line for non-earth fault using one-terminal data. IEEE Trans Power Delivery. 1999;14(3):863-67.

[11] Lin S, He ZY, Li XP, Qian QQ. Traveling wave time-frequency characteristic-based fault location method for transmission lines. IET Gen Trans Distrib. 2012;6(8):764-72.

[12] Wang B, Dong X, Lan L, Xu F. Novel location algorithm for single-line-to-ground faults in transmission line with distributed parameters. IET Gen., Trans Distrib. 2013;7(6):560-66.

[13] Zimath SL, Dutra CA, Matos RR, de Oliveira LB, de Resende JHM, Moutinho JAP. Traveling wave fault location applied to high impedance events. In: IET Int. Conf. Developments in Power System Protection, Copenhagen, Denmark, Mar.-April 2014: 1-6.

[14] Salehi-Dobakhshari A, Ranjbar AM. Application of synchronised measurements to wide-area diagnosis and locaiton. IET Cen Trans Distrib. 2014;8(4):716-29.

[15] Salehi-Dobakhshari A, Ranjbar AM. Robust fault location of transmission lines by synchronised and unsynchronised wide-area measurements. IET Cen Trans Distrib. 2014;8(9):1561-71.

[16] Gopakumar P, Reddy MJB, Mohanta DK. Transmission line fault detection and localisation methodology using PMU measurements. IET Cen Trans Distrib. 2015;9(11):1033-42.

[17] IEEE/PES Power System Relaying Committee. IEEE guide for determining fault location on ac transmission and distribution lines. New York: IEEE, 2014.

[18] Alexander GE, Mooney ], Tyska W: Advanced application guidelines for ground fault protection. In: 28th Annual Western Protective Relay Conf., Spokane, Washington, USA, Oct. 2001: 1-25

[19] Kulkarni S, Santoso S. Time-domain algorithm for locating evolving faults. IEEE Trans Smart Crid. 2012;3(4):1584-93.

[20] Costello D. Lessons learned analyzing transmission faults. SEL] Reliable Power. 2010;1(1):1-13.

[21] Suonan ], Xu Q, Li X, Liu S, Mao P. An evolving fault criterion for UHV transmission line protective relaying. Proceedings of the CSEE. 2006;26(4):93-98.

[22] Su B, Dong X, Sun Y. Impact of evolving fault on fault phase selector based on differential superimposed phase currents. In: IEEE Power Eng. Soc. Gen. Meeting, Toronto, Canada, July 2003: 2140-44.

[23] Sanaye-Pasand M, Khorashadi-Zadeh H. Transmission line fault detection \& phase selection using ANN. In: Int. Conf. Power System Transients, New Orleans, USA, Sept.-Oct. 2003: 1-6.

[24] Swetapadma A, Yadav A. All shunt fault location including cross-country and evolving faults in transmission lines without fault type classification. Electric Power Syst Res. 2015;123:1-12.

[25] ]iao X, Liao Y. Accurate fault location for untransposed/transposed transmission lines using sparse wide area measurements. IEEE Trans Power Delivery. 2016;31(4):1797-805.

[26] Rauhala T, Saarinen K, Latvala M, Uusitalo M Applications of phasor measurement units and wide-area measurement system in Finland. In: 2011 IEEE PowerTech, Trondheim, Norway, June 2011: 1-8.

[27] Terzija V, Valverde C, Cai D, Regulski P, Madani V, Fitch ], et al. Wide-area monitoring, protection, and control of future electric power networks. Proceedings of the IEEE. 2011;99(1):80-93.

[28] Dommel HW. Electromagnetic transients program reference manual (EMTP theory book). Vancouver, Canada: Department of Electrical Engineering, University of British Columbia, 1989.

[29] Nam SR, Park JY, Kang SH, Kezunovic M. Phasor estimation in the presence of DC offset and CT saturation. IEEE Trans Power Delivery. 2009;24(4):1842-49. 